${ }^{1}$ Институm клинической медицинь им. Н.В. Склифосовского

Первого Московского государственного медицинского университета им. И.М. Сеченова

${ }^{2}$ Университетская клиническая больнииза № 2 Первого Московского государственного медицинского университета им. И.М. Сеченова

\title{
Эффективность различных прандиальных регуляторов у пациентов с сахарным диабетом 2 типа и морбидным ожирением
}

\author{
В.В. Фадеев, д.м.н., проф. ${ }^{1}$, О.Ю. Гурова, к.м.н. ${ }^{1}$, И.В. Глинкина, к.м.н. ${ }^{1}$, \\ M.В. Амосова ${ }^{1}$, Е.С. Малолеткина ${ }^{2}$
}

Адрес для переписки: Мария Вадимовна Амосова, mariaamosova@mail.ru

Для цитирования: Фадеев В.В., Гурова О.Ю., Глинкина И.В. и др. Эффективность различных прандиальных регуляторов у пациентов с сахарным диабетом 2 типа и морбидным ожирением // Эффективная фармакотерапия. 2020. Т. 16. № 25. С. 12-18.

DOI 10.33978/2307-3586-2020-16-25-12-18

Выбор сахароснинающей терапии у пациентов с морбидным ожирением остается актуальной проблемой. В то же время исследований, оценивавиих особенности течения сахарного диабета у таких больных, до сих пор не проводилось.

В связи с этим было инициировано открытое проспективное рандомизированное исследование эфбективности разных препаратов преимущественно с прандиальным сахароснижающим эббектом в комбинации с базальным инсулином у пациентов с сахарным диабетом 2 типа и морбидным ожирением.

В исследовании принял участие 141 пачиент. Больных разделили на три группь. Первая группа получала агонист рецептора глюкагоноподобного пептида 1 в сочетании сметформином и базальным инсулином. Второй группе в дополнение $\kappa$ базальному инсулину и метформину был назначен препарат сульбонилмочевинь. Третья группа применяла традиционную базис-болюсную терапию с метформином. Исходно и через 24 недели исследования все участники прошли стационарное обследование, включавшее определение антропометрических показателей (рост, масса тела, окружность талии) и показателей углеводного обмена (глюкоза натощяак, постпрандиальная гликемия, гликированный гемоглобин). Кроме того, у них оценивалась частота гипогликемий.

Установлено, что у пациентов с сахарным диабетом 2 типа и морбидным ожирением в качестве прандиального компонента лечения препаратом выбора является агонист рецептора глюкагоноподобного пептида 1, возможно за счет его плейотропных эфбфектов.

В изелом с учетом наличия комплекса коморбидных состояний у таких больных проводимую сахароснинающую терапию необходимо персонализировать.

Ключевые слова: сахарный диабет, морбидное ожирение, инсулинотерапия, производные сульбонилмочевины, агонисты реиепторов глюкагоноподобного пептида 1

\section{Введение}

Актуальность темы определяется прогрессирующим ростом распространения сахарного диабета и ожирения, в том числе мор- бидной формы, а также высокой смертностью и ранней инвалидизацией таких пациентов [1-3]. Частое сочетание этих патологий привело к разработке саха- роснижающих препаратов, которые способны влиять не только на гликемический контроль, но и на контроль массы тела (не способствуют ее прибавке или даже снижают), обладают низким риском развития гипогликемий, благоприятным сердечно-сосудистым прогнозом [4]. Однако в рандомизированных клинических исследованиях эффективности сахароснижающих препаратов отдельно не рассматривались пациенты с морбидным ожирением, которые отличаются от общей группы больных [5-9]. Согласно классификации Национального института здравоохранения США, морбидное ожирение диагностируется при индексе массы тела $\left(\right.$ ИМТ) $\geq 35$ кг/ м $^{2}$ и наличии его серьезных осложнений, включая сахарный диабет 2 типа, или при ИМТ > 40 кг $/ \mathrm{M}^{2}$ вне зависимости от наличия осложнений $[10,11]$.

При лечении пациентов с сахарным диабетом 2 типа и морбидным ожирением прежде всего необходимо учитывать влияние сахароснижающих препаратов на увеличение массы тела и таким образом прогрессирование заболевания. Нередко лицам с сахарным диабетом 2 типа в силу большей доступности и распространенности назначают сахароснижающие препараты, способствующие при длительном приеме повышению массы тела. 
Это в свою очередь может привести к прогрессированию инсулинорезистентности и потребовать интенсификации лечения, назначения инсулинотерапии, что обусловливает дальнейшее увеличение массы тела. Необходимо отметить, что, несмотря на все имеющиеся средства фармакотерапии, в данной когорте больных сложности при попытках достижения компенсации углеводного обмена и снижения массы тела прежде всего возникают из-за невозможности соблюдения рекомендаций по питанию, изменения укрепившихся стереотипов пищевого поведения. К последним относится неконтролируемое и неограниченное число приемов пищи. Расстройство пищевого поведения затрудняет выделение пре- и постпрандиальных компонентов питания. Все это приводит к неэффективности стандартных схем сахароснижающей терапии.

При выборе методов лечения также следует учитывать многочисленные факторы риска, модифицирующие друг друга.

Целью нашего исследования стала оценка эффективности разных препаратов преимущественно с прандиальным сахароснижающим эффектом в комбинации с базальным инсулином у пациентов с сахарным диабетом 2 типа и морбидным ожирением.

\section{Материал и методы}

Проведено открытое проспективное рандомизированное исследование на базе клиники эндокринологии Первого Московского государственного медицинского университета им. И.М. Сеченова (Сеченовский Университет). Протокол исследования одобрен локальным этическим комитетом Сеченовского Университета.

Критерии включения пациентов в исследование:

- возраст старше 18 лет;

- сахарный диабет 2 типа;

- получение сахароснижающей терапии, включавшей базальный инсулин;

- ИМТ $\geq 35 \mathrm{\kappa г} / \mathrm{M}^{2}$;

- подписанное информированное согласие на участие в исследовании.
Критерии исключения:

- сахарный диабет 1 типа;

- острый панкреатит в течение последних пяти лет;

- беременность;

- кормление грудью;

- снижение скорости клубочковой фильтрации менее 45 мл/мин/1,73 м². В исследование был включен 141 пациент, находившийся на стационарном лечении в клинике эндокринологии Первого Московского государственного медицинского университета им. И.М. Сеченова с ноября 2015 г. по май 2018 г.

Участники исследования с помощью открытой блоковой рандомизации с использованием таблицы случайных чисел были разделены на три группы. Первая группа получала агонист рецептора глюкагоноподобного пептида 1 (арГПП-1) в сочетании с метформином и базальным инсулином, вторая - препарат из группы производных сульфонилмочевины (ПСМ) в дополнение к метформину и базальному инсулину, третья - традиционную базис-болюсную инсулинотерапию (ББИТ) в сочетании с метформином.

В качестве основных конечных точек выбраны значения массы тела, ИМТ, уровни гликированного гемоглобина (HbA1c), глюкозы плазмы натощак (ГПН) и постпрандиальной глюкозы (ППГ), частота гипогликемий и суточная доза инсулина.

Частота гипогликемий (гликемия менее 3,9 ммоль/л или тяжелая гипогликемия, потребовавшая посторонней помощи) оценивалась с помощью специально разработанного опросника, в котором пациенты самостоятельно указывали возникновение гипогликемии: 0 - отсутствие, 1 - до четырех раз в месяц (один раз в неделю), 2 - два раза в неделю, 3 - более трех раз в неделю, 4 - тяжелые гипогликемии.

Кроме того, больные должны были вести дневник самоконтроля в течение 10-14 дней перед включением в исследование и как минимум в течение двух недель перед каждым визитом к эндокринологу. Длительность наблюдения составила шесть месяцев (24 недели).
Анализ данных проведен в 2019 г. Их обрабатывали с помощью методов описательной статистики. Количественные переменные представляли в виде медианы, первого и третьего квартилей (Me $[25 ; 75])$, категориальные - в процентах. В качестве интервальных оценок для медианы использовали 95\%ный доверительный интервал (ДИ). Определение границ 95\% ДИ для биномиальных пропорций проводилось по методу Клоппера - Пирсона. Для установления различий между связанными выборками использовали критерий Вилкоксона. Статистическая значимость различий между группами определялась с помощью критерия Краскела Уоллиса (нулевая гипотеза об отсутствии различий отклонялась при $\mathrm{p}<0,05)$ с последующим применением критерия Данна (с использованием пошаговой коррекции p-значений по методу Холма). Для оценки динамики категориальных переменных в связанных выборках применяли критерий $\chi^{2}$ МакНемара. Для определения силы связи между количественными переменными использовали коэффициент корреляции Спирмена. Силу связи интерпретировали по шкале Чеддока. Вид зависимости признака от одного или нескольких признаков устанавливали с помощью логистического регрессионного анализа. Для анализа частоты развития гипогликемий применяли отрицательную биномиальную регрессию.

В качестве апостериорного анализа для попарных сравнений использовали тест Тьюки. Для оценки средних значений и 95\% ДИ зависимых переменных с учетом поправок на ковариаты (estimated marginal means) применялся подход, предложенный S.R. Searle и соавт. [12]. Различия между группами и ассоциации расценивались как статистически значимые при $\mathrm{p}<0,05$.

Все этапы предобработки и анализа полученных данных, а также визуализация выполнялись с использованием программы IBM SPSS Statistics 23.0 и среды для статистических вычислений R 3.5.3 (R Foundation for Statistical Computing). 


\section{Результаты}

Общая характеристика участников

В первой группе исходно был 61 пациент, во второй и третьей группах - по 40 пациентов. Однако в первой группе не все участники завершили исследование. Из пяти выбывших трое прекратили прием арГПП-1 в связи с развитием нежелательных явлений (тошнота, рвота, диарея), один - в связи с выраженной декомпенсацией углеводного обмена (гликемия от 20 до 24 ммоль/л), один - в связи с отсутствием финансовых возможностей приобретать препараты данного класса. Медиана возраста всех пациентов составила 60 [56; 67] лет, ИМТ - 36,8 $[35,0 ; 41,3] \kappa \Gamma / \mathrm{M}^{2}$. Исходный уровень HbAlc - 9,3 [8,1; 10,3]\%, что свидетельствовало о декомпенсации углеводного обмена. Стаж сахарного диабета 2 типа составил 12 [9; 17] лет. Характеристика участников исследования представлена в табл. 1.

Влияние прандиальных регуляторов на показатели углеводного обмена В первой группе уровень $\mathrm{HbAlc}$ исходно составлял 9,5 $[8,6 ; 10,8] \%$, во второй - 8,2 $[7,5 ; 9,6] \%$, в треть- ей $-9,45[8,50 ; 10,40] \%$. Через шесть месяцев терапии уровень HbAlc снизился до 7,6 [7,1; 8,5], $7,6[7,3 ; 8,1]$ и $7,9[7,5 ; 8,9] \%$ соответственно.

Различие между исходными и достигнутыми значениями $\mathrm{HbAlc}$ оказались статистически значимыми во всех группах $(\mathrm{p}<0,001)$. Однако динамика снижения HbAlc в группах существенно различалась (табл. 2, рис. 1). Наибольшим оно было у получавших арГПП-1.

Различие исследуемого показателя в группах арГПП-1 и ББИТ по сравнению с группой ПСМ было статистически значимым (р $<0,001$ и $\mathrm{p}=0,041$ соответственно), между группой арГПП-1 и группой ББИТ - на уровне статистической тенденции $(\mathrm{p}=0,052)$. Необходимо отметить, что за шесть месяцев в группе арГПП-1 доля пациентов с уровнем $\mathrm{HbAlc}$ $<7,5 \%$ увеличилась на $36,7 \%$ $\left(\chi^{2}=20,05 ; \mathrm{p}<0,001\right)$, в группе ББИТ - на $12,5 \%\left(\chi^{2}=1,778\right.$; $\mathrm{p}=0,182)$, в группе ПСМ на $7,5 \%\left(\chi^{2}=1,333 ; \mathrm{p}=0,248\right)$. Таким образом, доля достигших целевого уровня гликированно-

Таблииа 1. Характеристика участников исследования

\begin{tabular}{|l|l|l|l|l|}
\hline Показатель & Все пациенты & Группа арГПП-1 & Группа ПСМ & Группа ББИТ \\
\hline Количество, абс. & 141 & 61 & 40 & 40 \\
\hline Женский пол, абс. (\%) & $98(69,5)$ & $34(55,7)$ & $30(75,0)$ & $34(85,0)$ \\
\hline Возраст, лет & $60,0[56,0 ; 67,0]$ & $58,0[53,0 ; 66,0]$ & $63,0[57,8 ; 70,2]$ & $61,0[57,0 ; 66,0]$ \\
\hline $\begin{array}{l}\text { Масса тела, кг } \\
\text { ИМТ, кг/м }\end{array}$ & $105,0[96,0 ; 118,0]$ & $108,0[99,0 ; 120,0]$ & $98,0[92,2 ; 110,2]$ & $107,5[96,5 ; 118,0]$ \\
\hline $\begin{array}{l}\text { Длительность } \\
\text { сахарного диабета, лет }\end{array}$ & $12,0[9,0 ; 17,0]$ & $11,5[10,0 ; 16,2]$ & $11,0[6,5 ; 15,0]$ & $14,0[10,0 ; 20,0]$ \\
\hline $\begin{array}{l}\text { Уровень С-пептида, } \\
\text { пмоль/л }\end{array}$ & $542,5[415,0 ; 678,5]$ & $560,0[405,5 ; 669,5]$ & $512,5[417,2 ; 613,5]$ & $604,5[474,2 ; 801,2]$ \\
\hline НьА1с, \% & $9,3[8,1 ; 10,3]$ & $9,5[8,6 ; 10,8]$ & $8,2[7,5 ; 9,6]$ & $9,4[8,5 ; 10,4]$ \\
\hline $\begin{array}{l}\text { ГПН, ммоль/л } \\
\text { ППГ, ммоль/л }\end{array}$ & $9,9[8,6 ; 11,5]$ & $10,0[9,0 ; 12,0]$ & $8,4[7,5 ; 9,9]$ & $10,9[9,1 ; 12,0]$ \\
\hline $\begin{array}{l}\text { Суточная доза } \\
\text { инсулина, ЕД }\end{array}$ & $13,1[12,1 ; 14,4]$ & $13,5[12,4 ; 14,8]$ & $12,3[10,1 ; 13,3]$ & $13,8[12,5 ; 14,5]$ \\
\hline
\end{tabular}

Таблица 2. Динамика уровня НbА1с в разных группах терапии, \%

\begin{tabular}{|c|c|c|c|c|}
\hline \multirow[t]{2}{*}{ Группа } & \multicolumn{2}{|c|}{ Уровень НbA1с (Me $[25 ; 75])$} & \multirow{2}{*}{$\begin{array}{l}\text { Динамика HbA1c } \\
\text { (95\% ДИ) }\end{array}$} & \multirow[t]{2}{*}{ p } \\
\hline & исходно & через 6 месяцев & & \\
\hline арГПП-1 & $9,50[8,60 ; 10,80]$ & $7,60[7,10 ; 8,50]^{*}$ & $-1,60(-2,10--1,10)$ & $<0,001^{\star}$ \\
\hline ПСМ & $8,20[7,50 ; 9,60]$ & $7,60[7,30 ; 8,10]^{\star}$ & $-0,45(-0,90--0,25)$ & $<0,001^{\star}$ \\
\hline ББИТ & $9,45[8,50 ; 10,40]$ & $7,90[7,50 ; 8,90]^{\star}$ & $-1,20(-1,60--0,85)$ & $<0,001^{*}$ \\
\hline
\end{tabular}

* Изменение показателей статистически значимо $(\mathrm{p}<0,05)$. го гемоглобина была наибольшей при применении арГПП-1 (рис. 2).

На фоне терапии в трех группах также наблюдалось статистически значимое снижение ГПН и ППГ (табл. 3, рис. 3). В группе арГПП-1 уровень ГПН исходно составлял 10,00 ммоль/л (95\% ДИ 9,00-12,00), через шесть месяцев - 7,60 ммоль/л (95\% ДИ 7,00-8,80). Постпрандиальные показатели глюкозы исходно достигали 13,50 ммоль/л, через шесть месяцев снизились до 10,40 ммоль/л. Таким образом, ГПН уменьшилась на 2,40 ммоль/л (95\% ДИ -2,70- -1,90), ППГ на 2,85 ммоль/л (95\% ДИ-3,70- -2,50). В группах ПСМ И ББИТ указанный эффект был менее значительным. Уровень ГПН снизился на 0,55 ммоль/л (95\% ДИ $-0,85--0,30)$ и 2,30 ммоль/л (95\% ДИ $-3,00--1,70)$ соответственно, ППГ на 0,70 ммоль/л (95\% ДИ -0,90$-0,60)$ и 1,70 ммоль/л (95\% ДИ $-2,05--0,70)$ соответственно. Выраженное снижение постпрандиальной гликемии при применении арГПП-1 может быть ассоциировано с дополнительным влиянием препаратов данного класса на моторику желудка (ее замедление), а также на центры регуляции насыщения в центральной нервной системе.

Различие в динамике ГПН в группах арГПП-1 и ББИТ по сравнению с группой ПСМ было статистически значимым $(\mathrm{p}<0,001)$. В то же время между группами арГПП-1 и ББИТ статистически значимых различий по данному показателю не выявлено $(\mathrm{p}=0,51)$. Разница в динамике ППГ между всеми группами была статистически значимой: группа арГПП-1/группа ПСМ - $\mathrm{p}<0,001$, группа арГПП-1/группа ББИТ $\mathrm{p}=0,008$, группа ПСМ/группа ББИТ $-\mathrm{p}=0,018$.

Таким образом, наименьшее снижение уровня ГПН наблюдалось в группе ПСМ. В группах арГПП-1 и ББИТ показатели были сопоставимы. Однако в отношении динамики уровня ППГ терапия арГПП-1 превосходила другие виды лечения. 
Влияние терапии на суточную дозу инсулина

Динамика суточной дозы инсулина в трех группах представлена в табл. 4 и на рис. 4. Статистически значимое снижение дозы препарата зафиксировано только в группе арГПП-1. У получавших арГПП-1 она была уменьшена на 2 ЕД (95\% ДИ -2-0). В группах ПСМ и ББИТ выявлено значимое увеличение суточной дозы инсулина. Различия между группами были статистически значимыми: группа арГПП-1/группа ПСМ $\mathrm{p}<0,001$, группа арГПП-1/группа ББИТ - p < 0,001, группа ПСМ/группа ББИТ - $\mathrm{p}=0,006$. Такие результаты могут быть связаны как с эпизодами гипогликемии, так и с большими сложностями в достижении компенсации углеводного обмена.

\section{Эффекты прандиальных регуляторов на массу тела}

Через шесть месяцев терапии в группе арГПП-1 обнаружено статистически значимое снижение массы тела - -6,5 кг (95\% ДИ -9,0-4,0) (табл. 5, рис. 5). В группе ПСМ, наоборот, наблюдалось значимое увеличение массы тела - +1 кг (95\% ДИ 0-1). В группе ББИТ статистически значимых изменений не установлено. Различия в динамике массы тела были статистически значимыми только при сравнении группы арГПП-1 с группами ПСМ и ББИТ $(\mathrm{p}<0,0001)$. Необходимо напомнить, что тенденция к прибавке массы тела крайне нежелательна для пациентов с морбидным ожирением.

Через шесть месяцев терапии во всех группах статистически значимо изменился ИМТ ( $<<0,05)$ (табл. 6, рис. 6). Так, в группах ПСМ и ББИТ он увеличился на 0,1 кг/ $\mathrm{M}^{2}$ $\left(95 \%\right.$ ДИ 0,0-0,4) и 0,2 кг/ $\mathrm{M}^{2}(95 \%$ ДИ 0,0-0,5) соответственно. В группе арГПП-1 наблюдалось значительное снижение ИМТ - -2,7 кг/м ${ }^{2}$ (95\% ДИ -3,3- -1,9), что может свидетельствовать о благоприятном влиянии препаратов данного класса на пищевое поведение пациентов вследствие воздействия на центры регуляции насыщения центральной нервной системы. Различие в динамике ИМТ оказалось статистиче- ски значимым при сравнении получавших арГПП-1 с применявшими ПСМ и ББИТ $(\mathrm{p}<0,001)$.

\section{Вероятность развития гипогликемий} В таблице 7 представлены результаты анализа риска развития гипогликемий в зависимости от получаемого лечения. В качестве зависимой переменной выбрана частота развития гипогликемий через шесть месяцев терапии, в качестве поправочных ковариат - частота гипогликемий до начала терапии, возраст, пол и длительность диабета.

В группе арГПП-1 не выявлено ни одной гипогликемии, в то время как в группах ПСМ и ББИТ их частота составляла один-два раза в неделю. Кроме того, в группе ББИТ был зарегистрирован случай тяжелой гипогликемии.

Оценка вероятности отсутствия гипогликемий через шесть месяцев терапии без учета ковариата представлена в табл. 8 .

Результаты hurdle-модели для определения частоты развития гипогликемий через шесть месяцев терапии представлены в табл. 9. Полученные данные свидетельствуют о том, что тип назначенной терапии является значимым предиктором вероятности отсутствия и частоты развития гипогликемий. Применение арГПП-1 было ассоциировано с наименьшей вероятностью развития гипогликемии, поэтому является наиболее безопасным.

\section{Предикторы эффективности}

сахароснижающей терапии

К возможным предикторам эффективности терапии следует отнести продолжительность сахарного диабета 2 типа, возраст пациентов, уровень С-пептида (косвенный маркер секреторной активности $\beta$-клеток поджелудочной железы), ИМТ, исходный уровень HbA1c, ГПН и ППГ.

Результаты корреляционного анализа, проведенного для выявления

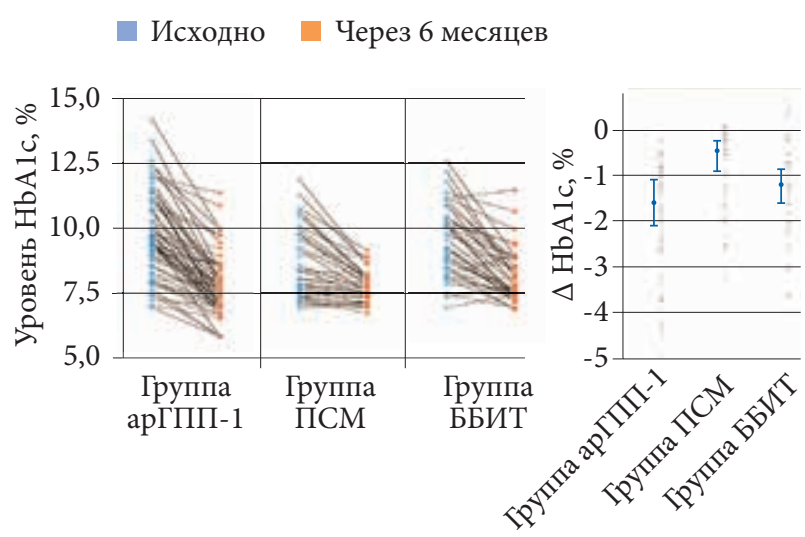

Рис. 1. Динамика уровня НbА1с в разных группах терапии

$\mathrm{HbA} 1 \mathrm{c}>7,5 \% \square \mathrm{HbA} 1 \mathrm{c}<7,5 \%$

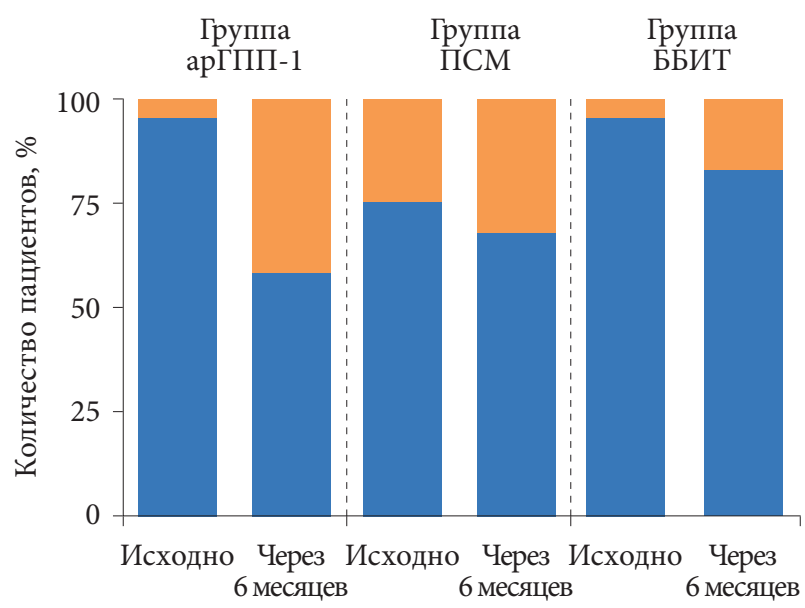

Рис. 2. Распределение пациентов в зависимости от уровня НbA1c

Таблица 3. Динамика тощзаковой и постпрандиальной гликемии в разных группах терапии, ммоль/л

\begin{tabular}{|c|c|c|c|c|}
\hline \multirow[t]{2}{*}{ Группа } & \multicolumn{2}{|c|}{ Концентрация глюкозы (Ме [25; 75]) } & \multirow{2}{*}{$\begin{array}{l}\text { Динамика гликемии } \\
\text { (95\% ДИ) }\end{array}$} & \multirow[t]{2}{*}{$\mathbf{p}$} \\
\hline & исходно & через 6 месяцев & & \\
\hline \multicolumn{5}{|c|}{ Глюкоза плазмы натощак } \\
\hline арГПП-1 & $10,00[9,00 ; 12,00]$ & $7,60[7,00 ; 8,80]^{*}$ & $-2,40(-2,70--1,90)$ & $<0,001^{\star}$ \\
\hline ПСМ & $8,40[7,50 ; 9,90]$ & $7,80[7,20 ; 8,60]^{\star}$ & $-0,55(-0,85--0,30)$ & $<0,001^{*}$ \\
\hline ББИТ & $10,90[9,10 ; 11,90]$ & $8,10[7,70 ; 9,00]^{\star}$ & $-2,30(-3,00--1,70)$ & $<0,001^{*}$ \\
\hline \multicolumn{5}{|c|}{ Постпрандиальная глюкоза } \\
\hline арГПП-1 & $13,50[12,40 ; 14,80]$ & $10,40[9,40 ; 12,40]^{*}$ & $-2,85(-3,70--2,50)$ & $<0,001^{\star}$ \\
\hline ПСМ & $12,30[10,10 ; 13,30]$ & $10,70[9,60 ; 12,50]^{*}$ & $-0,70(-0,90--0,60)$ & $<0,001^{*}$ \\
\hline ББИТ & $13,70[12,50 ; 14,50]$ & $12,10[10,10 ; 12,90]^{*}$ & $-1,70(-2,05--0,70)$ & $<0,001^{\star}$ \\
\hline
\end{tabular}

* Изменение показателей статистически значимо $(\mathrm{p}<0,05)$. 
ассоциации между снижением уровня HbA1с и исходными значениями потенциальных модифицируемых факторов, представлены в табл. 10. На рисунке 7 продемонстрирована связь исходных показателей углеводного обмена с динамикой $\mathrm{HbAlc}$.

Следует отметить, что наиболее существенное снижение $\mathrm{HbA1c}$ наблюдалось у пациентов с исходно более высокими его значениями $(\rho=-0,648, p<0,001)$.
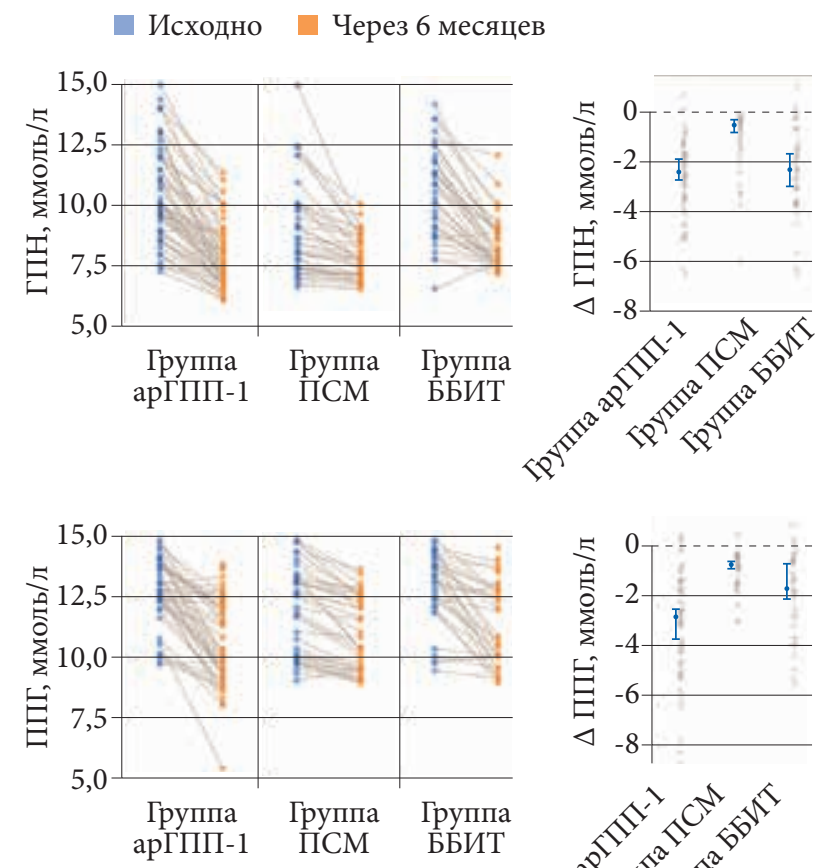

Кроме того, слабая статистически значимая отрицательная корреляция с динамикой $\mathrm{HbAlc}$ установлена для исходно высоких значений гликемии как натощак, так и постпрандиальной $(\rho=-0,223 ; p=0,086$ и $\rho=-0,537$; $\mathrm{p}<0,001$ соответственно). Однако при построении loess-кривой данная связь носила четко нелинейный характер, что может свидетельствовать о потенциально различной динамике $\mathrm{HbAlc} \mathrm{при}$ исходно высокой и исходно низкой гликемии. Поэтому рассматриваемый показатель не может считаться истинным предиктором эффективности терапии арГПП-1.

Значимым клинико-анамнестическим фактором эффективности арГПП-1 является возраст пациентов ( $\rho=0,333 ; p=0,009)$ (см. табл. 10). Статистически значимой связи с исходным ИМТ и стажем заболевания не обнаружено (см. табл. 10).

Поскольку в нашем исследовании участвовали только пациенты с морбидным ожирением, это может являться ограничением для применения полученных данных в других условиях.

\section{Вывод}

Полученные результаты свидетельствуют о том, что все исследуемые препараты потенциально эффективны. Так, во всех группах терапии наблюдалось снижение уровня $\mathrm{HbA1c}$, ГПН, ППГ, однако значимо большая положительная динамика отмечена в группе арГПП-1 (HbA1c - -1,6\%, ППГ -2,85 ммоль/л). Скорее всего, это связано с замедлением опорожнения желудка, а также подавлением аппетита на фоне терапии арГПП-1.
Важным моментом при проведении сахароснижающей терапии является достижение компенсации углеводного обмена без увеличения риска развития гипогликемий. В отношении частоты развития легких гипогликемий статистически значимых различий между группами ПСМ и ББИТ не выявлено (11,5 против $12,7 \%$; $\mathrm{p}>0,05)$. Однако в группе ББИТ был зарегистрирован один случай тяжелой гипогликемии. В то же время в группе арГПП-1 не было зарегистрировано ни одного случая гипогликемии. Проведенный анализ вероятности развития гипогликемий также продемонстрировал преимущество арГПП-1.

Ключевым моментом при выборе сахароснижающей терапии пациентам с морбидным ожирением является ее влияние на массу тела. Принимая во внимание прогрессирующую прибавку массы тела на фоне ББИТ, трудности, возникающие при попытках снижения веса, особенности пищевого поведения пациентов, важно подобрать такую схему лечения, которая бы позволила достичь целевой гликемии без риска увеличения массы тела. Во всех трех группах отмечалось значимое изменение ИМТ. Так, в группах ПСМ и ББИТ он увеличился на 0,1 и 0,2 кг $/ \mathrm{M}^{2}$, в группе арГПП-1 снизился на 2,7 кг/ $\mathrm{m}^{2}$.

Кроме того, в группе арГПП-1 удалось значимо снизить суточную дозу инсулина, тогда как в группах ПСМ и ББИТ наблюдалось ее увеличение.

Таким образом, среди всех вариантов сахароснижающей терапии, включающей в себя базальный инсулин, для пациентов с сахарным диабетом и морбидным ожирением наиболее опти-

Таблица 4. Динамика суточной дозы инсулина в разных группах терапии, ЕД

\begin{tabular}{|c|c|c|c|c|}
\hline \multirow[t]{2}{*}{ Группа } & \multicolumn{2}{|c|}{ Доза инсулина (Ме $[25 ; 75])$} & \multirow{2}{*}{$\begin{array}{l}\text { Динамика } \\
\text { суточной дозы } \\
\text { инсулина } \\
\text { (95\% ДИ) }\end{array}$} & \multirow[t]{2}{*}{ p } \\
\hline & исходно & через 6 месяцев & & \\
\hline арГПП-1 & $30,0[25,0 ; 42,0]$ & $32,0[24,0 ; 40,0]^{\star}$ & $-2,0(-2,0-0,0)$ & $0,026^{*}$ \\
\hline ПСМ & $16,0[12,0 ; 18,5]$ & $18,0[16,0 ; 24,0]^{*}$ & $4,0(2,0-4,0)$ & $<0,001^{*}$ \\
\hline ББИТ & $85,0[73,5 ; 100,5]$ & $100,0[84,0 ; 118,0]^{\star}$ & $8,0(7,0-14,0)$ & $<0,001^{\star}$ \\
\hline
\end{tabular}

Рис. 4. Динамика суточной дозы инсулина в разных группах терапии

* Изменение показателей статистически значимо $(\mathrm{p}<0,05)$. 
Таблица 5. Динамика массы тела у пациентов в разных группах терапии, кг

\begin{tabular}{|c|c|c|c|c|}
\hline \multirow[t]{2}{*}{ Группа } & \multicolumn{2}{|c|}{ Масса тела (Ме $[25 ; 75])$} & \multirow{2}{*}{$\begin{array}{l}\text { Динамика } \\
\text { массы тела } \\
\text { (95\% ДИ) }\end{array}$} & \multirow{2}{*}{ p } \\
\hline & исходно & через 6 месяцев & & \\
\hline арГПП-1 & $108,5[98,3 ; 120,0]$ & $105,0[93,3 ; 114,8]^{*}$ & $-6,5(-9,0--4,0)$ & $<0,0001^{*}$ \\
\hline ПСМ & $98,0[93,0 ; 110,5]$ & $98,0[93,0 ; 110,0]^{*}$ & $1,0(0,0-1,0)$ & $0,0162^{*}$ \\
\hline ББИТ & $109,0[97,5 ; 118,0]$ & $113,0[100,0 ; 121,0]^{*}$ & $2,0(-6,0-10,0)$ & $0,5530^{*}$ \\
\hline
\end{tabular}

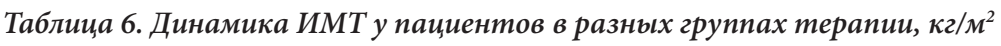

\begin{tabular}{|c|c|c|c|c|}
\hline \multirow[t]{2}{*}{ Группа } & \multicolumn{2}{|l|}{ ИМТ (Me $[25 ; 75])$} & \multirow{2}{*}{$\begin{array}{l}\text { Динамика ИМТ } \\
\text { (95\% ДИ) }\end{array}$} & \multirow[t]{2}{*}{$\mathbf{p}$} \\
\hline & & & & \\
\hline & & & & \\
\hline & & & & \\
\hline ББИТ & $38,20[35,95 ; 43,10]$ & $39,00[36,00 ; 43,25]$ & $0,20(0,00-0,50)$ & $0,004^{*}$ \\
\hline
\end{tabular}

* Изменение показателей статистически значимо $(\mathrm{p}<0,05)$.

Таблица 7. Частота развития гипогликемий в неделю

\begin{tabular}{|c|c|c|c|c|}
\hline \multirow[t]{2}{*}{ Группа } & \multicolumn{2}{|c|}{ Оценка без учета ковариата } & \multicolumn{2}{|c|}{ Оценка с учетом ковариата } \\
\hline & $\begin{array}{l}\text { средняя частота } \\
\text { гипогликемий } \pm \\
\text { стандартная } \\
\text { ошибка }\end{array}$ & $\operatorname{Me}[25 ; 75]$ & $\begin{array}{l}\text { средняя частота } \\
\text { гипогликемий } \pm \\
\text { стандартная } \\
\text { ошибка }\end{array}$ & 95\% ДИ \\
\hline арГПП-1 & $0,082 \pm 0,035$ & $0[0 ; 0]$ & $0,000 \pm 0,003$ & $0,000-0,006$ \\
\hline ПСМ & $2,000 \pm 1,129$ & $1[0 ; 2]$ & $2,805 \pm 1,263$ & $2,284-1,326$ \\
\hline ББИТ & $1,775 \pm 1,141$ & $1[0 ; 1]$ & $1,645 \pm 1,269$ & $1,112-1,177$ \\
\hline
\end{tabular}

Таблица 8. Вероятность отсутствия гипогликемий

\begin{tabular}{|l|l|l|}
\hline Группа & Частота без учета ковариат & $\mathbf{9 5 \%}$ ДИ \\
\hline арГПП-1 & 0,92 & $0,85-0,99$ \\
\hline ПСМ & 0,33 & $0,16-0,50$ \\
\hline ББИТ & 0,43 & $0,24-0,62$ \\
\hline
\end{tabular}

Таблица 9. Результаты анализа роst hoс попарных различий вероятности отсутствия и развития гипогликемий через шесть месяцев терапии

\begin{tabular}{|c|c|c|c|}
\hline Группы сравнения & Разница & 95\% ДИ & p \\
\hline \multicolumn{4}{|c|}{ Вероятность отсутствия гипогликемий } \\
\hline Группа арГПП-1 vs группа ПСМ & $-0,59$ & $0,36-0,82$ & $<0,0001$ \\
\hline Группа арГПП-1 vs группа ББИТ & $-0,49$ & $0,24-0,73$ & $<0,0001$ \\
\hline Группа ПСМ vs группа ББИТ & $-0,10$ & $-0,40-0,19$ & 0,6797 \\
\hline \multicolumn{4}{|l|}{ Частота развития гипогликемий } \\
\hline Группа арГПП-1 vs группа ПСМ & $-0,805$ & $-1,429--0,181$ & 0,0076 \\
\hline Группа арГПП-1 vs группа ББИТ & $-0,645$ & $-1,283--0,007$ & 0,0470 \\
\hline Группа ПСМ vs группа ББИТ & $-0,160$ & $-0,654-0,975$ & 0,8866 \\
\hline
\end{tabular}

Таблица 10. Корреляция между снижением уровня НbА1с и потенциальными предикторами эффективности терапии арГПП-1

\begin{tabular}{|l|l|l|}
\hline Предикторы эффективности терапии & $\boldsymbol{\rho}$ Спирмена & $\mathbf{p}$ \\
\hline Исходный уровень НЬА1с & $-0,648$ & $<0,001$ \\
\hline Исходный уровень С-пептида & $-0,116$ & 0,376 \\
\hline Исходный уровень ГПН & $-0,223$ & 0,086 \\
\hline Исходный уровень ППГ & $-0,537$ & $<0,001$ \\
\hline Возраст & 0,333 & 0,009 \\
\hline Длительность сахарного диабета & 0,212 & 0,105 \\
\hline ИМТ & $-0,148$ & 0,261 \\
\hline
\end{tabular}

Исходно Через 6 месяцев

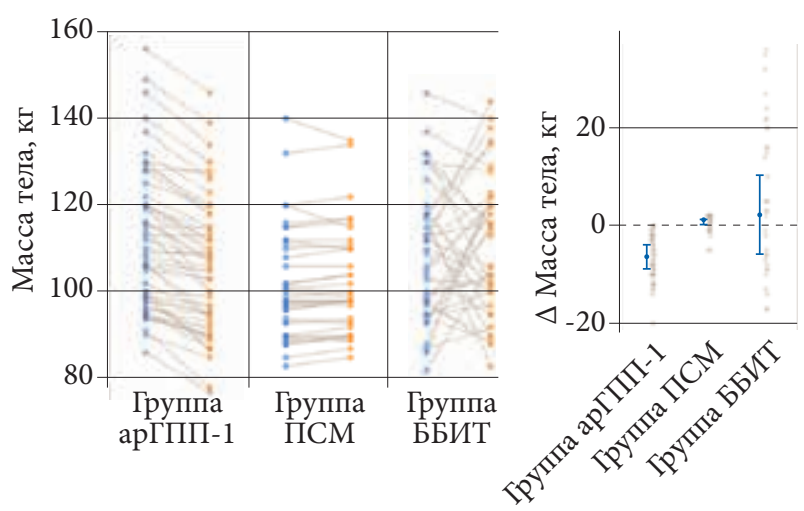

Рис. 5. Динамика массы тела в разных группах терапии

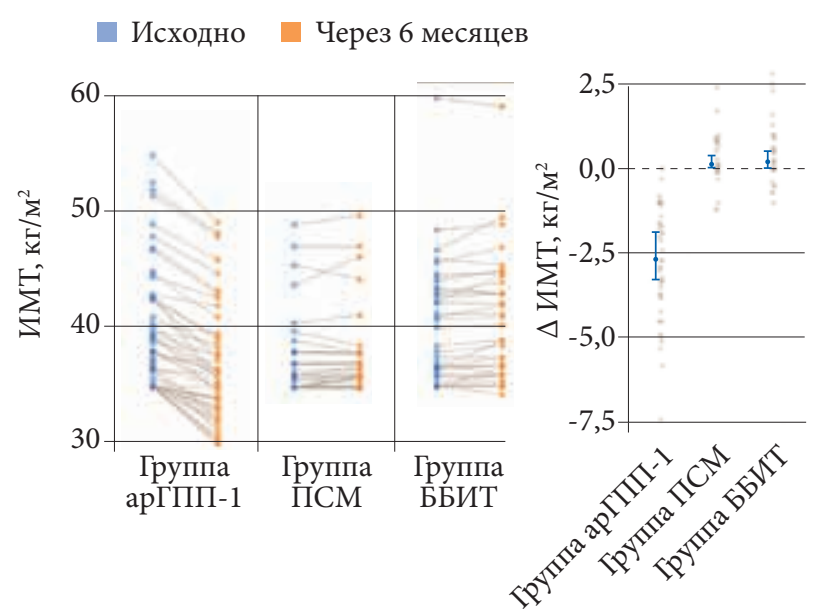

Рис. 6. Динамика ИМТ в разных группах терапии
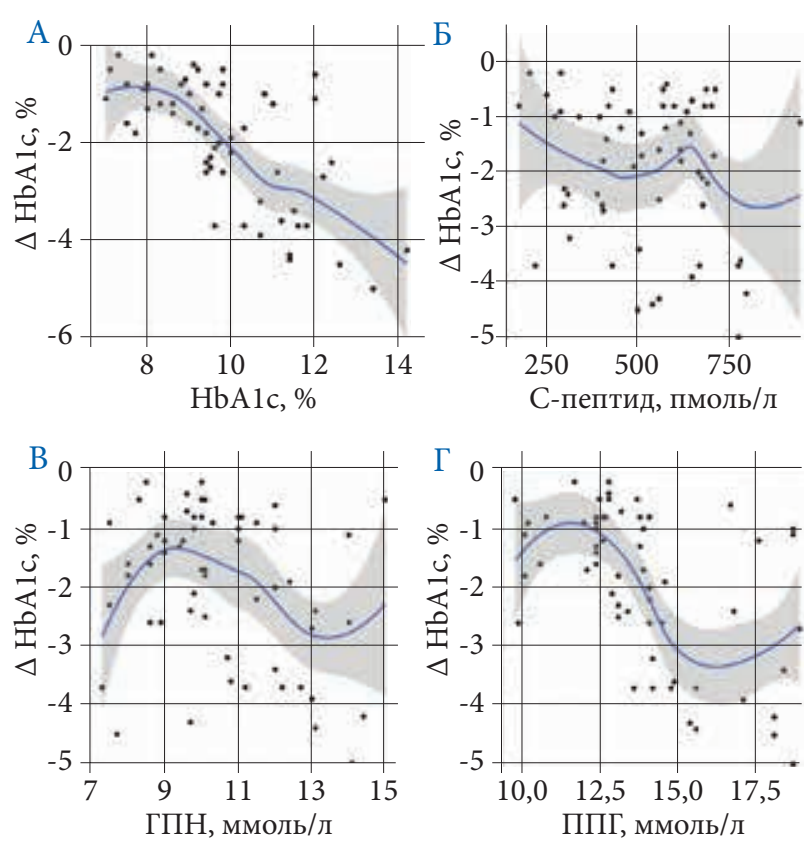

Рис. 7. Предикторы эффективности арГПП-1 
мальной и безопасной является комбинация базального инсулина и арГПП-1, что обеспечивает воздействие на разные звенья патогенеза обоих заболеваний и, как следствие, улучшение показателей углеводного обмена, массы тела без риска развития гипогликемий.

Результаты исследования представляют значимый клинический интерес. Они могут быть применены в работе с пациентами, а также стать основой для разра- ботки протоколов будущих проспективных исследований.

Авторь декларируют отсутствие явньх

u потенииальных конфликтов интересов, связанньх

с публикаиией настоящей статьи.

\section{Литература}

1. International Diabetes Federation. Diabetes Atlas. $9^{\text {th }}$ ed. Brussels, 2019.

2. https://www.who.int/ru/news-room/fact-sheets/detail/diabetes.

3. https://www.who.int/news-room/fact-sheets/detail/obesity-and-overweight.

4. Lau D.C., Teoh H. Impact of current and emerging glucose-lowering drugs on body weight in type 2 diabetes // Can. J. Diabetes. 2015. Vol. 39. № 5. P. S148-S154.

5. Meier J.J. GLP-1 receptor agonists for individualized treatment of type 2 diabetes mellitus // Nat. Rev. Endocrinol. 2012. Vol. 8. № 12. P. 728-742.

6. Orme M.E., Nguyen H., Lu J.Y., Thomas S.A. Comparative effectiveness of glycemic control in patients with type 2 diabetes treated with GLP-1 receptor agonists: a network meta-analysis of placebo-controlled and active-comparator trials // Diabetes Metab. Syndr. Obes. 2017. Vol. 10. P. 111-122.

7. Мехдиев С.Х., Мустафьев И.И., Мамедов М.Н. Оценка эффективности лечения пациентов с сахарным диабетом 2-го типа при использовании различных схем терапии // Казанский медицинский журнал. 2017. Т. 98. № 4. С. 564-571.

8. Cai X., Ji L., Chen Y. et al. Comparisons of weight changes between sodium-glucose cotransporter 2 inhibitors treatment and glucagon-like peptide-1 analogs treatment in type 2 diabetes patients: a meta-analysis // J. Diabetes Investig. 2017. Vol. 8. № 4. P. 510-517.

9. Calvert M.J., McManus R.J., Freemantle N. Management of type 2 diabetes with multiple oral hypoglycaemic agents or insulin in primary care: retrospective cohort study // Br. J. Gen. Pract. 2007. Vol. 57. № 539. P. 455-460.

10. Дедов И.И., Мельниченко Г.А., Шестакова М.В. и др. Национальные клинические рекомендации по лечению морбидного ожирения у взрослых. 3-й пересмотр (Лечение морбидного ожирения у взрослых) // Ожирение и метаболизм. 2018. № 1. С. 53-70.

11. Clinical Guidelines on the Identification, Evaluation, and Treatment of Overweight and Obesity in Adults - The Evidence Report. National Institutes of Health // Obes. Res. 1998. Vol. 6. Suppl. 2. P. 51S-209S.

12. Searle S.R., Speed F.M., Milliken G.A. Population marginal means in the linear model: an alternative to least squares means // The American Statistician. 1980. Vol. 34. № 4. P. 216-221.

\section{Effectiveness of Different Prandial Regulators in Patients with Type 2 Diabetes and Morbid Obesity}

V.V. Fadeev, MD, PhD, Prof. ${ }^{1}$, O.Yu. Gurova, $\mathrm{PhD}^{1}$, I.V. Glinkina, $\mathrm{PhD}^{1}$, M.V. Amosova ${ }^{1}$, E.S. Maloletkina ${ }^{2}$

${ }^{1}$ Sklifosovsky Institute of Clinical Medicine of I.M. Sechenov First Moscow State Medical University

${ }^{2}$ University Clinical Hospital No. 2 of I.M. Sechenov First Moscow State Medical University

Contact person: Mariya V. Amosova, mariaamosova@mail.ru

The choice of hypoglycemic therapy in patients with morbid obesity remains the urgent problem. At the same time, studies evaluating the features of treatment of diabetes in such patients have not yet been conducted. In this regard, an open prospective randomized study of the effectiveness of various drugs, mainly with prandial hypoglycemic effect in combination with basal insulin in patients with type 2 diabetes and morbid obesity was initiated. The study involved 141 patients. The first group received glucagon-like peptide 1 receptor agonist in combination with Metformin and basal insulin. In the second group, in addition to basal insulin and Metformin, the sulfonylurea drug was added. The third group used traditional basal-bolus therapy with Metformin. Initially and after 24 weeks of the study, all participants underwent the hospital examination, which included the determination of anthropometric indicators (height, body weight, waist circumference) and indicators of carbohydrate metabolism (fasting glucose, postprandial glycaemia, glycated hemoglobin). In addition, the frequency of hypoglycemia was assessed. It was found that in patients with type 2 diabetes and morbid obesity, the drug of choice as prandial component of treatment is the agonist of the glucagon-like peptide 1 receptor, possibly due to pleiotropic effects. In general, taking into account the presence of the complex of comorbid conditions in such patients, the ongoing hypoglycemic therapy should be personalized.

Key words: diabetes mellitus, morbid obesity, insulin therapy, sulfonylurea derivatives, glucagon-like peptide 1 agonists 